\title{
Capítulo III \\ Diferencia entre hacer política, hablar de política y escribir pendejadas en las redes sociales
}

lo hora de abordar las condiciones básicas (actuales) para ha-
blar de política en Colombia, no se puede concebir un mediano acercamiento a un acuerdo general o a una conclusión más o menos acertada, si no se establece la distinción que evocaré en el presente capítulo. Si bien hoy, la televisión y la radio continúan manejando los hilos de la opinión mediática, desde hace un par de décadas, la Internet y más propiamente las redes sociales han ingresado a acaparar los espacios de ocio, información, educación, interacción, divulgación, exclamación, competencia y discusión, entre otras acciones, en la vida de las presentes generaciones.

Los más veteranos de la sociedad colombiana claman por un "uso responsable" de las redes, de la Internet, porque ven su utilidad, pero temen reconocer el efecto monumental que ha tenido desplazando poco a poco la vieja sociedad fundada exclusivamente en los valores modernos o en la confianza, a mi juicio absurda, del "famoso" ciudadano responsable; ese cuento es muy viejo, la responsabilidad es un concepto que le pasa lo mismo que a la política en Colombia, está tan cargado de desconfianza, está tan violado, tan oculto, que inclusive en el campo del deporte, particularmente 
el futbol, vemos cómo los medios y la opinión en general a la hora de referirse a un jugador colombiano que ya no es una gran estrella simplemente porque ya no es bueno o ya le "pasó su hora", prefieren culpar al club, a la FIFA y hasta al Papa de ser necesario, antes de aceptar la realidad.

En Colombia es habitual, que los gobernantes gobiernen echando la culpa de todo al anterior gobierno. Es habitual que entre las entidades se "tiren la batuta" sobre quién es la responsable. No, definitivamente no; en Colombia la responsabilidad es como para los fracasados, el exitoso es el que escapa a la responsabilidad y sale invicto.

La responsabilidad en Colombia merecería otro capítulo, no obstante, hago hincapié en ella, porque caen en la ingenuidad o en el absurdo aquellos que piden un manejo "responsable" de la Internet.

Muy bien, volvamos pues, al eje del presente capítulo, incitando la curiosidad del lector con algunas preguntas: ¿se puede hablar de política en Colombia dejando a un lado el efecto, y más que el efecto, la realidad manifiesta que está contenida en las redes sociales? Usted podría dudar o tal vez estar de acuerdo conmigo.

La verdad, yo creo que no. Evidentemente, no cualquiera que escriba "pendejadas" en las redes sociales consigue un golpe de opinión mediático. ¿Qué considero un golpe de opinión mediático? Debo aclarar que este concepto no es un gran desglose filosófico político de una cuestión, es más, creo que ronda en la misma sencillez con que miramos nuestro celular y ojeamos un rato las redes. Un golpe de opinión mediático es un efecto que comienza con una declaración, con un trino, con un posteo, con la publicación de una foto que realiza un personaje (casi siempre público o impulsado por algún personaje público) generando controversias en los medios, luego trasladando la controversia de los medios a la calle y de la calle en ocasiones a los salones de clase, dando como resultado, que sin más ni menos, por un efecto mediático simple, 
la sociedad en general nos hallemos hablando, discutiendo y hasta intercambiando improperios por la idea susodicha.

Uno de los golpes de opinión que recuerdo como más útiles para mis cátedras, fue una declaración del prestigioso abogado Abelardo de la Espriella en que afirmaba que el derecho no tenía nada que ver con la ética (ElTiempo.com, 2015). Esto generó debate al interior de las universidades, vi a mucha gente indignada con la cuestión, luego recordé y propuse en mis cátedras que finalmente no había que alterarnos, puesto que los colombianos comunes y corrientes, sabemos que el derecho en Colombia en ocasiones no tiene nada que ver con la justicia. Y si equiparamos justicia y ética como monumentos axiológicos, entonces, eso puede tranquilizarnos frente a opiniones de este estilo, que viajaron rapidísimo en razón de los medios.

No obstante, es importante saber, que no toda pendejada que posteamos en las redes se constituye en un golpe de opinión. ¿'Tiene que ser una opinión erudita y retórica? No. De hecho, una pendejada puede constituirse en un golpe de opinión, lo importante por saber es quién publica e impulsa dicha opinión, bien sea una gran idea o una pendejada. La tecnología no hace política. No. Eso es lo mismo que tratar a los medios como si fueran sujetos, mucha gente anda enredada en el debate sobre los medios de comunicación y yo siempre lo he argumentado: ni son de comunicación ni son sujetos ${ }^{1}$. Los medios son eso, cosas, herramientas, tecnologías, que son propiedad de personas con intereses públicos o privados. No basta con que cualquiera tenga el último celular y postee todos los días algo en las redes sociales para que se constituyan los golpes de opinión, hasta ese punto no llega la tecnología porque a pesar de que esté en manos de todos, los hilos de la política siguen

1 En capítulos subsiguientes me adentraré en esta idea. 
siendo manejados, independientemente del medio, por personajes públicos con presencia en el poder económico y político.

Así que si cualquier sujeto escribe un par de pendejadas en su Facebook, probablemente solo interesará a los siete individuos que lean dichas exclamaciones, pero sin duda no se constituirá en un golpe de opinión, como sí pasa por ejemplo con muchos funcionarios públicos y su cuenta de Twitter.

Empero, en el marco de esta breve explicación, surge un nuevo interrogante, que convoca a reflexionar si la fórmula está completa hasta el momento. Veamos: tenemos un personaje público y este personaje usa las redes sociales, hasta allí ¿qué hace falta? ¿Es suficiente una red social y un personaje público para constituir golpes de opinión? A decir verdad, podría añadir que a una figura pública no le basta el Twitter por el Twitter por muy figura pública que sea, ¿qué sería de los trinos de un funcionario si no fueran promovidos por un medio de información masivo? La verdad, tengo mis dudas sobre su impacto.

Entonces, hay una claridad básica, y es que si hoy la televisión y la radio están aparentemente siendo desplazadas por las redes sociales, son ellas, solo en la voz de las grandes cadenas masivas, las que se encargan de configurar los golpes de opinión per se. En este marco, el presente capítulo quiere ofrecer una propuesta de diferenciación entre hacer política, hablar de política y escribir pendejadas en las redes sociales, sencillamente, porque esta distinción elemental entre las tres acciones se constituye en una condición básica para hablar de política en Colombia.

Quiero comenzar, exponiendo en primer lugar lo que correspondería a hacer política. ¿Hacer política es insertarse en los mecanismos del sistema electoral con fines lucrativos o clientelistas? Efectivamente no. Sin embargo, inserto esta pregunta venenosa porque la política, como muchas otras cosas en Colombia, se ha constituido también en un negocio individual. 
Prosiguiendo, un colombiano promedio ante la pregunta sobre el quehacer de la política, inmediatamente aludiría que significa corrupción, trampa y toda una serie de adjetivos que emergen como respuesta a la frustración que traté de exponer en el capítulo anterior. No obstante, si antes del quehacer, nos preguntamos por el qué es, sugiero la siguiente definición:

Política significa la aspiración a participar en el poder o a influir en la distribución del poder entre los distintos Estados o, dentro de un mismo Estado, entre los distintos grupos de hombres que lo componen. Esto se corresponde esencialmente con la acepción habitual del término. Cuando se dice que una cuestión es política, o que son políticos un ministro o un funcionario, o bien que una decisión ha sido políticamente condicionada, lo que se quiere siempre decir es que la respuesta a esa cuestión, o la determinación de la esfera de actividad de aquel funcionario, o las condiciones de esta decisión, dependen directamente de los intereses existentes sobre la distribución, la conservación o la transferencia del poder. (Weber, 1919, p. 2)

Distribución, conservación o transferencia del poder... si me limitara a esta definición, entonces, tendría que seguir esa línea dura e inflexible de las definiciones conceptuales que convierten un concepto en un mar de elementos que parecen monstruos de ocho cabezas, donde cada cabeza tiene ocho lenguas, cada una con una cabeza iy así!... entonces, algo que debería quedar claro de una manera sencilla, se convierte en un maremágnum apto para iluminados. Aclaro antes de proseguir que no quiero decir que la política sea algo simple, pálido o fácil de asumir y comprender, de hecho, jamás me ha gustado comparar el concepto sencillez, con algún tipo de condición peyorativa relativa a un tema, creo yo que algo más apropiado y lo que sí he evocado en mis cátedras es la comprensión clara, concisa, contextualizada y no tan densa, tan arbitrariamente "ladrilluda" de los conceptos o las ideas. 
Recapitulando la definición de política, me gusta mucho más la de Andrade (1990, p. 5), en la cual indica que "política implica una forma específica de comportamiento humano que se relaciona con el gobierno, con la dirección de una colectividad, con ciertas pautas de acción para la dirección de un grupo y con el conocimiento de estas cuestiones". Esta definición es mucho más concluyente a pesar de que tiene un par de palabras menos; Andrade la despeja del exclusivo esquema del poder, y sin aislarla de esa realidad intrínseca, deja abierta la interpretación a lo que significa grupo o colectividad, permitiendo correlacionar aquello que implica "lo político" con escenarios diferentes al Estado.

Entonces, recogiendo lo mejor de ambas definiciones, puedo decir que es una diada que siempre está presente a la hora de hablar de política, en principio se asocia con los temas de interés público haciendo referencia a la relación con el Estado y el poder, pero también, se relaciona con el interés colectivo, comunitario, que avanza y ha avanzado en la historia sin la mano de los Estados, tratando a la vez de no desmitificar la existencia del poder, más sí, desvirtuando que su única fuente sea el Estado.

Por consiguiente, la respuesta a la pregunta ¿qué es hacer política? podría orientarse comprendiendo que se trata de una acción que logra desarrollar un grupo de sujetos, que se organizan buscando el acceso o el cumplimiento de un objetivo común. La razón sociológica de la política no es específicamente la colectividad, como sí lo es la asociación, y la asociación debemos vincularla al plano de una facultad humana.

Más aún en la sociedad contemporánea, donde la degradación del liberalismo, es decir el individualismo, sigue copando tantos escenarios culturales y sociales, creo más que pertinente considerar hacer política como aquella facultad humana que nos otorga el beneficio de la asociación. Una facultad que es difícil de ejecutar, si lo pensamos desde la asociación más primigenia, hoy ya no estamos dispuestos a consolidar una relación de pareja sin contemplar 
problemas o restas a nuestra supuesta libertad, los compromisos generan duda porque en la sociedad de los ganadores, en la sociedad del éxito, pareciera que perder no fuera parte de la vida humana.

En resumen, hacer política, es consolidar un escenario para el desarrollo de la facultad que he mencionado. Hacer política no es engañar para el ascenso a un cargo público, hacer política no es comprar votos. Eso de los votos, además de ser un derecho, también es un proceso que se deriva de la mercadotecnia política inserta en el sistema electoral, un sistema que en Colombia tan solo a la luz de la materia estadística, siempre queda en ridículo ante la gran masa de no votantes que siempre arrasan promoviendo implícitamente en la acción de no votar, que lo malo no es negarse al voto, sino seguir apoyando un sistema que está viciado de fondo... Bueno imagino que algún lector dirá: si no votamos ¿entonces qué hacemos?... a lo cual responderé coherentemente: ipolítica!

Hacer política no es entonces comprar tamales, lechona, aguardiente o combos escolares para repartir entre la gente menos educada y así conseguir votos. Tampoco es ir a las universidades hablar de un par de proyectos ficticios o citar a un par de autores y así conseguir votos entre los más educados; hacer política no es hacer de los lobbies los portavoces de una minoría ignorada. No, nada de lo anterior es política, insisto, eso es mercadotecnia y tráfico de influencias; si hago alusión a estos ejemplos que rayan en lo infantil señalando aquello que no constituye hacer política, definitivamente lo hago porque desde esta práctica primigenia inicia el engaño, no importa la medida de la educación, hoy es un gran defecto creer que la educación per se "libera", la verdad tengo mis dudas.

En Colombia caen presos de un sistema electoral corrupto los menos educados y los más educados, puesto que, al tratarse de mercadotecnia, resulta más fácil convencer a un individuo ofreciendo dádivas personales, en vez de la persecución de grandes objetivos colectivos o algún tipo de idea que implique compromiso, sacrificio o contacto... es decir, a los más pobres y poco educados se les 
engaña con lo que más les conviene al igual que a los más educados se les engaña con lo que más les conviene, no es una ambigüedad, es una realidad del sistema preferentemente individualista.

Retomando la disertación, hacer política es arrojarse a la acción por un objetivo común, es restar prioridad al individuo, entregarse a la colectividad, pero no para perderse entre lo que Alain Touraine denomina "la comunidad autoritaria que suprime al sujeto y lo aleja de la realidad, por lo tanto, de la posibilidad de transformarla" (Touraine, 1997, p. 65). En realidad, si existe un primer momento de entrega a la colectividad, es ni más ni menos, para salvaguardar las posibilidades individuales. De este modo se desarrolla entonces un efecto político, conjunto, colectivo, para que después de cumplido el objetivo común, podamos regresar al bienestar individual dando gracias y créditos al valor colectivo de la acción.

Sin duda el planteamiento es complejo, pero no imposible. En Colombia todos los días gente común y corriente practica la política, aquella que depende y no depende del Estado, pues como una facultad ontológicamente humana, solo se necesita un espacio de reflexión y un tiempo para la acción, una acción en principio sí y solo sí, colectiva.

En segundo lugar, intentaré dar una breve respuesta a qué significaría, en el marco de la triada ofrecida en el presente capítulo, hablar de política.

Esto, tiene un grado de explicación algo más complejo, a saber: para hablar sobre cualquier tema, lo que mínimamente se debe poseer son conocimientos sobre el tema en cuestión, de esta manera, se podrá asegurar lógicamente que se está hablando de ese tema y no de otra cosa.

Ahora bien (y esto es fundamental) sin unas condiciones básicas que impliquen como mínimo un pequeño o mediano conocimiento para hablar sobre un tema en cuestión, sencillamente se podría 
concluir que no se está hablando sobre dicho tema, sino tal vez aludiendo a símiles, incoherencias, o elementos totalmente diferentes.

Entonces, correlacionando las definiciones evocadas anteriormente, hablar de política, en principio es hablar sobre alguna forma de gobierno, alguna forma de dirección de una colectividad, es hablar sobre el poder, sobre su distribución, sobre cómo conservarlo, cómo arrebatarlo, cómo celebrarlo.

Algo que facilita aún más la comprensión de lo que significa hablar de política es que cuando hablamos de política también podemos estar hablando sobre ideologías. "La Ideología es para el Destutt una ciencia completa del hombre, que abarca incluso las cuestiones del "querer" y del "obrar" (Quintana, 2007, p. 207). Quintana cita a Destutt quien acuñó por vez primera el término "ideología", y aporta a la construcción inicial del concepto, al involucrar el querer y el obrar.

Cuando se habla de ideologías, o de ideología, la polisemia triunfa sobre la definición certera, no obstante, considero que, con el fin de no ahondar en asuntos innecesarios para este capítulo, concordaré en que hablar de ideología, es hablar de ideas que se quieren y, Por lo tanto, de ideas por las que se es capaz de obrar. No hay conclusión más bella a la que Destutt llega involucrando a la psicología en su conformación del concepto ideología: "pensar es sentir" (Destutt citado por Quintana, 2007, p. 207).

Bien, si pensar es sentir, si la política está cargada de ideas que se quieren y por las que se obra, si hablar de política implica hablar

2 Se puede comprender ideología como aquel principio propuesto por Carlos Marx, según el cual las ideas no pueden explicarse a partir de sí mismas, con independencia del contorno social en el que aparecen. Desde otra perspectiva, según Max Horkheimer la ideología es todo pensamiento ligado al ser, que arraiga a una determinada situación social. No obstante, para ampliar y ahondar en este concepto, la ideología ha de comprenderse a partir de tres raíces: la crítica a la filosofía del Estado de Hegel, a la antropología de Feuerbach y a la economía política clásica (Lenk, 2000). 
de dirigir una colectividad, de conservar o arrebatar el poder, entonces ya es hora de afirmar que hablar de política no es hablar sobre la corbata de un funcionario o sobre cuánto dinero gastó en su cuarta boda. Hablar de política no es discutir sobre las tendencias sexuales de una persona, hablar de política no es denigrar sin fundamentos de un presidente, hablar de política no es hablar sin fundamentos de un grupo político organizado, hablar de política no implica agregar a toda conclusión el adjetivo "mierda".

Como un elemento adicional, que complejiza el análisis, eso que yo denomino "hablar sin fundamentos", en realidad está fuertemente relacionado con algunos fundamentos. ¿Es acaso una incoherencia o una redundancia lo que estoy planteando? Consideraría que no. Existen por ejemplo aquellos fundamentos que los medios de información masivos promueven en Colombia, aquellas percepciones que se construyen en las salas de edición y redacción de los medios masivos. ¿Es factible que se constituya una información superflua y falaz, que funciona como fundamento en muchas personas que finalmente la consideran suficiente para creer que hablan de política?

En verdad para asegurar esto habría que desarrollar una investigación específica. No obstante, a priori puedo mencionar algo con lo que el lector probablemente esté de acuerdo y es que los medios de información evidentemente informan, más no ofrecen la posibilidad de conocer; es decir, quiero asegurar que entre informar y conocer existe una brecha más profunda que la fosa de las Marianas ${ }^{3}$.

Por una parte, conocer implica un esfuerzo, dedicación, búsqueda, un ensayo y error en torno a la conclusión, implica descarte de opciones, una visión desde distintos planos; conocer involucra el esfuerzo por romper la unilateralidad (en este caso) de la

3 El lugar más profundo del océano hasta ahora conocido. 
información masiva y construir una multilateralidad de ideas y menciones que componen el elemento por conocer en sí.

Por otra parte, informar es algo muy diferente. Quiero detenerme en cómo el modelo vertical de la comunicación basado esencialmente en Harold Lasswell dio forma al esquema, emisor-mensaje-receptor y que fue perfeccionado por Wilbur Schramm y David Berlo con un nuevo esquema mensaje-canal-receptor-efecto (Beltrán, 2005). Esta forma vertical de la comunicación es lo que denomino Informar. El ciclo en esencia funciona de la siguiente forma (figura 1).

Figura 1. Esquema vertical de comunicación

\section{Realidad en la que están contenidos A y B}

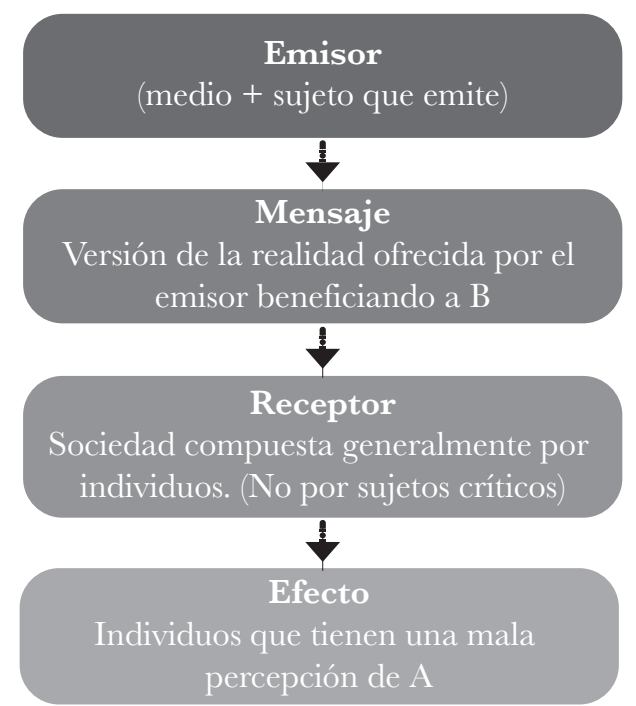

Fuente: elaboración propia.

En la figura 1 se puede apreciar un esquema vertical que denota básicamente lo siguiente: en primer lugar, una realidad de la cual nadie es dueño y en esencia, para no entrar en un debate 
filosófico impertinente, afirmaré que dicha realidad es una sola. Ahora bien, en esa realidad puede haber contenidos, sujetos, cosas, tendencias que he denominado al azar A y B. Entonces, el primer paso de este ciclo es el de un emisor con una característica un poco diferente a lo que siempre hemos catalogado como emisor, es decir, no solo es un sujeto. Es un sujeto más un medio a su disposición. ¿Por qué es importante tener presente que en la figura 1 el emisor es un compuesto bífido? Porque como he insistido, un medio no es algo que tenga vida, un medio solo es una herramienta a disposición de los sujetos. En resumen, en este primer paso, el emisor ofrece una versión de la realidad, dicha versión es una variable dependiente del sujeto que utiliza el medio.

El mensaje es consecuentemente esa versión de la realidad que ha presentado el emisor. Ahora bien, supongamos que el emisor tiene los mismos intereses que B, es decir todos los contrarios de A; el mensaje ya ha sido emitido, con una carga que beneficiará a B; el siguiente paso en este ciclo es el receptor. ¿Quién es el receptor? ¿Gente que se toma el trabajo de investigar las cosas que le están narrando como un mínimo necesario para no ser engañada? ¿O más bien son personas que por lo general escuchan o leen a duras penas titulares, pero no están prestas a preguntarse absolutamente por nada más allá que no emita su canal de información?

Para dar sostenibilidad al esquema, prefiero quedarme con algo que sabemos por consenso: la sociedad colombiana en líneas generales no es una sociedad crítica, es decir, no somos una sociedad donde la mayoría de la población tiene acceso a educación superior o que desarrolla hábitos de lectura que abren un espectro de conocimiento que para otros es limitado en razón del trabajo, la pobreza, las deudas y los ambientes sociales.

Ahora bien, si condimento con fatalismo esta cuestión, ya ni los universitarios componen una sociedad crítica, sino un cuerpo social endeudado para mantener estatus frente al consumo, con una mente más o menos entregada a lo que la ideología Master of 
Business Administration (MBA) proponga y a cuanta cosa ofrezca el mercado del ocio, excepto preguntarse por su lugar en la sociedad o las posibilidades de transformación social. Por lo tanto, y como último paso del ciclo, se consolida un efecto: la percepción desarrollada por el emisor, facilitada por una sociedad con un nivel crítico bajo. En el ejemplo hipotético, finalmente la percepción que se forja la sociedad de $\mathrm{A}$ es absolutamente negativa, frente a la que se tiene de $\mathrm{B}$.

Lo que quiero decir es que la gente solo se informa, no conoce, no tiene y pareciera que ni quiere la posibilidad de acceder a medios de comunicación como tal y el riesgo de perecer entre la percepción y las opiniones vacías es tan alto, que es preferible educar a discutir "pendejamente".

En un ejemplo más explícito: los colombianos observamos ciertas tendencias de algunos medios $¿$ Dichas tendencias son de los medios? En efecto y luego de la explicación de la figura 1 la tendencia es forjada por el sujeto que domina o es dueño del medio. Ahora bien, y creo que esta es una tesis fundamental que he argumentado en la reciente etapa de mi ejercicio docente, en Colombia ¿hablamos de medios masivos de comunicación? Evidentemente, no. Lo que existe aquí son medios de información, porque la mayoría de los colombianos se informan, pero no entran a conocer lo que un emisor les está entregando. Informarse es diferente a conocer, porque para conocer necesitamos medios de comunicación, es decir, canales participativos que poco o nada tienen que ver con las encuestas que uno ve por ahí. En conclusión, y como abrebocas de lo que desarrollaré en el capítulo sobre el problema de la objetividad (capítulo 5) creo que necesitamos liberarnos de los medios de información y buscar verdaderos medios de comunicación o crearlos si en su defecto no existen.

Ahora bien, recapitulando, muchísima gente en Colombia considera que habla de política, construyendo su discurso a partir de los elementos que les ofrecen exclusivamente los medios 
masivos de información, entonces, cuando se desarrolla una conversación basada en algo que usted no conoce, sino en algo sobre lo cual meramente le han informado, las probabilidades de lograr un diálogo útil, lejos de opiniones absurdas, conclusiones vacías y hasta estúpidas, son demasiado pequeñas.

Si quiere recibir un buen consejo de estas humildes letras que aquí escribo: no se meta en una discusión con personas que solo se informan; para hablar de política, basta con conocer, pero no solo con informarse de una única fuente discursiva. Eso constituye, como vengo diciendo y desarrollaré más adelante, un moldeamiento unilateral de su visión y es lo que precisamente ha traído más problemas a nuestra sociedad contemporánea, la inamovilidad de los individuos para arriesgarse a conocer, para tomarse el trabajo de entender, y no solo quedar a merced de un discurso unilateral llamado "información" que viaja de manera masiva y que, al final, fue pensado solo por un grupo de personas muy reducido, eso que teóricamente se denomina Emisor.

Finalmente, hablar de política significa que usted conoce de política, habla de dirigir una colectividad, de conservar o arrebatar el poder, pero atención: con esto no me refiero a que para hablar de política usted tenga la necesidad de forjarse necesariamente como politólogo o filósofo político; a decir verdad, si vuelvo a evocar mi fatalismo característico, muchos politólogos están insertos en estudiar para perfeccionar la mercadotecnia de la política, y muchos filósofos están empecinados en alejarse cada vez más de la sociedad con sus conclusiones excesivamente ideales. Es verdad, soy un atrevido porque eso es una generalización sin piedad y sin fundamento teorizado. No obstante, cómo nos duelen las generalizaciones.

Aquí en Colombia nadie se escapa y como autor de estas letras, trato de traducir la rabia de un colombiano promedio con sus intelectuales... a veces tan lindos, tan bien hablados, tan leídos, tan cerca, pero a la vez tan, tan, tan, lejos. 
¡Definitivamente no! para hablar de política no es estrictamente necesario estudiar una carrera afín, es importante que para comprobar que sí se está hablando de política, una persona, con o sin pergaminos, está hablando de dirigir una colectividad, de conservar o arrebatar el poder, de organizarse colectivamente para solicitar, para protestar, para reivindicar, etc. allí estamos hablando de política.

Cuándo un trabajador discute con sus compañeros sobre cómo solicitar al jefe la posibilidad de mejoras salariales ¿está hablando de política? Sí. Cuándo los estudiantes deciden redactar una carta, argumentando por qué un docente no conviene a la facultad, ¿se está hablando de política? Sí. Cuándo un grupo de tecnólogos decide realizar una protesta por recortes presupuestales, ¿¿se está hablando de política? Sí. Cuándo un grupo de personas se organizan en la sala de un hospital y solicitan hablar con la gerencia en razón del mal servicio, ¿'se está hablando de política? Sí. Hablar de política es poner en el escenario de los objetivos comunes, la posibilidad de realizarlos. Si se realiza la abstracción más elemental de la primera sociedad humana (una pareja) ¿estamos hablando de política? En abstracto y en la práctica definitivamente sí, el amor, es el catalizador humano de la primera relación política por antonomasia.

Por último y, en tercer lugar, intentaré dar una breve respuesta sobre qué significaría entonces, en el marco de la triada que he venido desglosando, escribir pendejadas en las redes sociales. Es probable que el lector esté intuyendo una degradación en los conceptos que he venido presentando, y que pueda considerar a las redes sociales como un cuerpo estéril en un debate serio sobre la política. No obstante, cuán equivocados estamos cuando damos la espalda al contexto, a la coyuntura, a lo folclórico y delimitamos nuestra incertidumbre, con esa mala maña de considerar que lo sabemos todo o lo que es peor, que poseemos el criterio para categorizar cuáles cosas son valiosas y cuáles no en términos del conocimiento. Muy 
bien, para hablar de las redes sociales previamente quiero invitar al lector a evaluar que las redes sociales se encuentran insertas en la realidad social del mundo contemporáneo; lo que es importante reconocer ipso facto es que dicha realidad es una realidad virtual.

¿Existen dos tipos de realidad? ¿Una física y una virtual? Responderé brevemente estos interrogantes, sin "salirme por la tangente", sino más bien asumiendo una disciplina orientadora. Considero que ahondar en ese debate desde la filosofía es desproporcionar los límites de la paciencia que el lector tiene con estas letras tan escuetas que estoy presentando; por tal motivo, no quiero mencionar la existencia de dos realidades en términos filosóficos, empero sí, en términos sociológicos.

La lógica social que vivimos, por ejemplo, en encuentros cara a cara, cuando nos acercamos a la persona que nos gusta, cuando nos referimos a aquel que no nos cae muy bien es bastante diferente de cómo se desarrolla la interacción virtual. De hecho, según Goffman, para cubrir ese "yo" que en verdad somos, en un encuentro cara a cara, utilizamos estrategias de protección del "yo", construimos una fachada, realizamos interpretaciones dramáticas de nuestros roles para mantener una línea adecuada en un acto con otras personas, mantenemos cuidadosamente un control expresivo, evitamos la tergiversación de nuestros roles, delimitamos nuestra conducta de acuerdo con los escenarios en los que interactuamos, porque la interacción, ese cara a cara, es ante todo un acto, y este solicita la interacción simbólica (Goffman, 1959). ¿Qué pasa con todo esto en la interacción virtual? Se pierde. La interacción virtual no depende de la interacción simbólica que pervive en un cara a cara y por eso se ha constituido en un escenario de libertad para el "yo" más profundo que tenemos.

Entonces, antes de seguir exponiendo lo que será esta tercera definición, es importante mencionar que la realidad virtual se constituye como el escenario de las redes sociales y es algo más complejo de lo que parece, va mucho más allá de la condición 
desmitificadora que muchas personas le imprimen, a veces solo por haber crecido en otro tipo de ambientes, bajo condiciones sociológicas específicas.

Hoy, la realidad virtual es tan importante como la realidad fisica; ambas, en términos sociológicos, tienen unas condiciones muy diferentes y por ende unas posibilidades inimaginables de constitución de nuevos campos sujetos de comprensión.

Hasta el momento, he definido muy brevemente aquello de la realidad virtual. Pero entremos en materia y respondamos a la pregunta: ¿Qué se considera una red social en Internet?

Una red social en Internet es una comunidad de usuarios registrados en un portal web que comparten información, interactúan entre ellos mediante mensajes y cuentan con otras formas de colaboración [...] además de poder compartir información por medio de una red social, a veces nos encontramos ante la necesidad de un espacio colaborativo en el que cada miembro de esa comunidad pueda depositar sus aportaciones personales. (Cascales, Real \& Marcos, 2011, p. 4)

Una red social es entonces una compleja conexión de usuarios y más usuarios que están afiliados gratuitamente a un portal específico, y esencialmente mantienen la lógica dinámica de la humanidad: interactúan en ese ciberespacio llamado Internet. Esta primera definición nos arroja a la conclusión inicial y es que una red social es un medio por donde puede viajar información y conocimiento de manera exponencial, pues, según Cascales, Real y Marco (2011), un usuario tiene en promedio 100 contactos y un solo mensaje, sea el que sea, puede llegar automáticamente a 10.000 personas. Eso es un nivel que ni con la radio ni con la televisión se llegó a soñar. La premisa de esa gran escala es un factor determinante que atrae la atención de grandes grupos de medios informativos para copar dichos escenarios. 
No obstante, por ejemplo, las grandes cadenas de medios informativos se enfrentan actualmente a una realidad con la que por mucho tiempo no tuvieron que lidiar; me refiero a las respuestas airadas de la gente ante sus notas informativas, es decir, la pieza que hacía falta en un esquema comunicativo: la respuesta del otro, los comentarios, los "me gusta", los "no me gusta" y una serie de apreciaciones decentes o groseras que quedan inscritas en sus propias páginas, esperando a ser vistas por más cibernautas, que particularmente, en Colombia han constituido dos cosas. Una, los improperios que no pasan a mayores entre gente común, y la segunda, los golpes de opinión entre los comentarios de personajes públicos que son retransmitidos por esos grandes medios: la radio y la televisión.

Este nuevo fenómeno al que se enfrentan los medios, el de la gente cuestionando sus noticias, promoviendo aplausos o censuras, este fenómeno se generó cuando "el cibernauta accedió a la condición de prosumidor. Debemos reconocer a los prosumidores como los actores comunicativos de la sociedad de la ubicuidad" (Islas-Carmona, 2008, p. 29). Si un prosumidor es un actor comunicativo, entonces, cualquiera podría afirmar que las oportunidades de transformación y descentralización del poder mediático estaban abiertas. No obstante, no sucedió así. ¿Por qué? ¿Por qué no se descentralizó ese poder mediático si ya podíamos con la Internet acceder a todos los medios del mundo, incluso crear uno propio y publicar las verdades o mentiras que quisiéramos? ¿Por qué las grandes cadenas siguieron configurando la opinión y esa tendencia de la gente por informarse antes que comprender o conocer los hechos? Básicamente por dos razones. La primera: la combinación entretenimiento e información. La segunda: el empalme metodológico entre televisión, radio y portal en Internet.

Respecto de la primera razón, la combinación entre entretenimiento e información forjó el camino obvio de la desconexión del individuo con la realidad política, si se aleja a un individuo de 
la realidad, entonces dicho individuo tendrá menos posibilidad de transformarla y será, por ende, mucho más maleable. Un individuo que pasaba de ver el titular de alguna masacre paramilitar durante la primera década del siglo XXI en Colombia, continuaba con el triunfo de la selección Colombia o el lanzamiento de un nuevo reality show. Entre lo que duraba la mención sobre la masacre paramilitar y toda la parafernalia frente al lanzamiento del reality show, el individuo perdía la noción de preguntarse por algo más, y seguía cómodamente entregado al instante del entretenimiento. El entretenimiento se retuvo más tiempo que la instantánea informativa, y ante los anuncios de seguir en Internet la emisión online del siguiente o la repetición del capítulo, la televisión se convirtió en la puerta del contenido en Internet.

Respecto de la segunda razón, en Internet, las grandes cadenas de medios, también se sumaron como prosumidores al esquema Facebook y Twitter, potenciando los alcances que se obtenían en el mundo virtual enfocándolos a la radio y la televisión, dándole primicia ya no solo a un hecho acontecido en la realidad física, sino a una discusión en redes sociales entre los personajes que ellos eligieran, total, con la televisión tenían un público asegurado, solo restaba fidelizarlo en la Internet y sin duda lo lograron. El individuo puede ir a mil sitios web, pero en razón de la escala que paulatinamente produce una tendencia, y como esta a su vez genera una influencia, finalmente siempre está pendiente de lo que las redes y portales específicos (los mismos de la televisión y la radio) dicen, insisto, no para analizar una información, sino para asumir que esa es la realidad per se.

La filosofia de las redes sociales se basa en el principio de comunidad abierta y no jerarquizada, que vincula a los usuarios mediante un tema o actividad común y una plataforma web (software social) que permite a los usuarios operar de manera sencilla e intuitiva en lo que se conoce como ámbito de las $3 \mathrm{C}$ (content, construction and colaboration) (Cascales, Real \& Marcos, 2011, p. 5). 
Modus operandi de las redes sociales: contenido, construcción y colaboración. Esta filosofía de las redes sociales, mencionada por Casales, Real \& Marcos, me permite comenzar a esbozar la definición de lo que significa, sobre todo en el contexto colombiano, escribir pendejadas en las redes sociales. ¿Contenido? ¿Qué contenido puede evocar un individuo que no se pregunte por la realidad y se anime a superar la información para pasar a conocer? ¿Construcción? Si por construcción se hace referencia a la construcción de intereses entre usuarios, ¿qué tipo de intereses se configuran, más allá de los mercantiles, en una sociedad que solo se informa, pero poco conoce de política? La respuesta aquí es inmediata: se configuran los intereses del emisor, visto como ese sujeto que es famoso en la televisión, es famoso en la radio y por ende tendrá seguidores en Twitter. ¿Colaboración? ¿Qué tipo de colaboración se configura en una entramada red de interacción virtual? Bueno, creo que este último punto de la filosofía de las redes sociales es del que más hablamos cuando reconocemos que mantenerse conectado mediante redes sociales (virtuales) con los amigos y amigas o familiares constituye una ayuda eficaz para solicitar favores instantáneos.

No obstante, debo llamarme al orden, porque aquí no estoy realizando un análisis a las redes sociales y sus distintos usos; lo que importa aquí es reconocer en términos políticos qué es escribir pendejadas en las redes sociales, y para ello he llegado hasta la definición de la filosofia de las redes, para que se entienda que no estoy descartando su uso, ni elaborando una serie de argumentos para cerrar diciendo que las redes sociales son el peor daño que le pudo pasar a la humanidad, que nos tienen viciadas las relaciones interpersonales o gritar como un pobre moralista con discurso refrito, que "prefiero tomarme un café que chatear" ipor favor! Podemos hacer ambas cosas sin que eso se convierta en un atributo cliché de perfil intelectual. 
La cosa es así, lo expondré mediante preguntas orientadoras o problemáticas, porque ellas constituyen el desarrollo de mi propio debate, que al final consolidará una definición satisfactoria o debatible, pero consistente. ¿Puede cualquier persona escribir en las redes sociales? Por supuesto, inclusivamente, cualquiera. ¿Eso constituye una pendeja? Claro que no, quienes aseguran esto son los moralistas a los que me refería en el párrafo anterior. ¿Un posteo en redes sociales constituye por sí solo un golpe de opinión política? No. Una cosa es que cualquiera escriba algo y se agarre con todos los que le hagan comentarios negativos a su publicación y otra cosa es que un personaje público escriba algo y su publicación sea potenciada por grandes cadenas de radio y televisión. Es decir, que el golpe de opinión no depende del personaje que postee en redes sociales; inclusive, puede ser un personaje estudiado o ignorante, y eso no le permite el ascenso a la opinión general. Lo que constituye la opinión o los golpes de opinión política es la aplicación del trinomio televisión, radio y portal web, de las grandes cadenas de medios.

Lo que permite concluir que escribir en las redes sociales es un derecho de cualquiera que tenga acceso a Internet. Además, cualquier "alguien" muy educado o sagaz puede hacer un gran comentario, que lejos de ser un comentario pendejo, puede quedarse como una opinión arrojada al vacío de la no-réplica, es decir, sin repercusión.

¿Cuántos políticos que son prácticamente odiados por las grandes cadenas de medios quisieran ser escuchados o promovidos al menos con la misma contundencia con la que se promueve el Twitter de algunos funcionarios? Ya hemos visto abiertas confrontaciones entre gobernantes y medios informativos, seguimos viendo la relación casi sexual que tienen algunos medios con algunos funcionarios; vemos también que aquí para algunos medios, la opinión de un líder indígena vale tres minutos al aire, pero la opinión de un gran industrial, vale una hora al aire. Entonces 
¿cuáles "posteos" se constituyen en pendejadas? Aquellos posteos realizados por los individuos que solo se informan y no se atreven a conocer. Esos posteos significan escribir pendejadas en las redes sociales, pues ni están hablando de política y mucho menos se constituirán en golpe de opinión.

A lo mejor el lector recuerda alguno que otro comentario tonto en redes; no haré mención textual de ninguno porque siento que sería antiestético, pero la verdad hay tanto prosumidor escribiendo pendejadas sin fundamento que no vale la pena detenerse por una pendejada.

Que la Internet entonces ¿ha perdido una capacidad heurística? Por supuesto que no. Es solo que esa capacidad está disponible para sujetos críticos o esos brillantes autodidactas, y en Colombia abundan los individuos que prefieren informarse (en vez de conocer) para terminar posteando pendejadas en las redes sociales.

Como gran conclusión de este capítulo, quiero recapitular al lector en que el propósito del mismo, fue realizar la distinción entre hacer política, hablar de política y escribir pendejadas en las redes sociales. Fui mencionando una a una las definiciones, para terminar anclando la conclusión final como una condición básica para hablar de política en Colombia, pues ahora que se tiene un panorama propositivo de una distinción, el lector bien puede discutir con mis ideas o por lo menos centrar una claridad y es que sin dicha distinción, hablar de política se convierte en una verborrea que no conduce a nada, a lo mejor a ganarse enemigos cibernautas, a lo mejor a que le salgan más canas, a lo mejor a seguir impulsando la felicidad de esos emisores insertos en los grandes medios informativos, que les conviene desde todo punto de vista, que se sigan reproduciendo individuos que no pregunten, que no cuestionen y que se entretengan con cualquier pendejada. 